\title{
Chapter 11 \\ Psychosocial and Patient Support Services in Comprehensive Cancer Centers
}

\author{
Rajshekhar Chakraborty, Navneet S. Majhail, and Jame Abraham
}

\section{Introduction}

As the number of cancer survivors continues to increase due to a rising cancer incidence, better treatment, and early detection, there is a growing need for comprehensive psychosocial and supportive care at comprehensive cancer centers. Based on cancer incidence and survival statistics in the United States, the number of cancer survivors will increase to 20 million by 2026 [1]. Supportive care services not only benefit patients who are cured or have achieved long-term remission, but also those living with metastatic disease. However, despite current guidelines on survivorship care, many recommendations have not been uniformly implemented across cancer centers. For example, in a survey conducted by the American Psychological Oncology Society [APOS], approximately half of the clinical cancer centers did not offer routine psychosocial screening for new cancer patients [2]. The Institute of Medicine [IOM] has also framed several key recommendations to ensure that cancer survivors are not lost in transition after completing active treatment [3]. Hence, strategically addressing both psychosocial and physical effects in cancer survivors should be an important treatment goal that needs to be uniformly addressed by comprehensive cancer centers [4]. In this chapter, we will discuss the key psychosocial

\footnotetext{
R. Chakraborty $(\bowtie)$

Columbia University Medical Center, New York, NY, USA

e-mail: rc3360@cumc.columbia.edu

N. S. Majhail

Blood and Marrow Transplant Program, Department of Hematology-Oncology, Cleveland

Clinic Taussig Cancer Center, Cleveland, OH, USA

e-mail: navneet.majhail@sarahcannon.com

\section{J. Abraham}

Department of Hematology-Oncology, Cleveland Clinic Taussig Cancer Center,

Cleveland, $\mathrm{OH}$, USA

e-mail: abrahaj5@ccf.org
} 
and supportive care services that are required as a part of survivorship programs at comprehensive cancer centers. We will discuss the services required for managing common psychosocial and physical effects experienced by cancer survivors and the current models of survivorship care. Pharmacologic management of psychosocial and physical issues in cancer survivors are outside the scope of this chapter and will not be discussed here. Palliative care and hospice are an important component of comprehensive cancer care and are discussed in detail in Chap. 9. Table 11.1 describes various domains that fall within the purview of cancer center patient support services and psychosocial care and the resources recommended for their effective management.

\section{Common Psychosocial and Physical Effects}

\section{Distress and Mood Disorders}

The National Comprehensive Cancer Network (NCCN) defines distress as an unpleasant experience of psychological, social, spiritual, and/or physical nature that may hinder the ability of patients to cope effectively with cancer or its treatment [5]. Distress is prevalent in approximately one-third of cancer survivors and can be associated with a reduced quality of life [6, 7]. Furthermore, patients experiencing distress have a lower likelihood of adhering to recommended health behaviors and surveillance strategies [8]. Mood disorders, including anxiety, depression, or post-traumatic stress disorder [PTSD] is also prevalent among cancer survivors and warrants screening by the oncologist or primary care physician [PCP] [4]. A meta-analysis showed the odds ratio of PTSD in cancer survivors to be 1.66 compared to controls [9].

Screening for distress, anxiety, and depression is recommended by the NCCN survivorship guidelines. The NCCN distress thermometer along with other tools such as PHQ9 can be easily administered prior to clinic visit such that the clinician and appropriate support staff [e.g., social worker or financial navigator] can be notified.

\section{Services Required for Management}

Patients who display signs of anxiety, depression, or distress on initial screening should be thoroughly evaluated by the oncologist regarding any physical cause related to cancer or anticancer therapy. Furthermore, safety evaluation, such as suicidal intent, safety at home, and social isolation, should be conducted by appropriate personnel. Access to licensed social workers experienced in caring for cancer patients or a dedicated psycho-oncologist is desirable for initial evaluation prior to referring 
Table 11.1 Various domains of services for patient support and psychosocial care within comprehensive cancer centers

\begin{tabular}{|c|c|c|}
\hline Domain & Personnel support & Infrastructure support \\
\hline Advance care planning & Social worker & Clinic space \\
\hline Care coordination & $\begin{array}{l}\text { Care coordinators, patient } \\
\text { navigators, nurse navigators }\end{array}$ & $\begin{array}{l}\text { Clinic space, technology support to } \\
\text { facilitate care coordination }\end{array}$ \\
\hline Community outreach & $\begin{array}{l}\text { Care coordinators, social } \\
\text { worker, patient navigator }\end{array}$ & $\begin{array}{l}\text { Cancer screening, infrastructure to } \\
\text { facilitate referral and access to care, } \\
\text { outreach programs for underserved } \\
\text { populations, community education }\end{array}$ \\
\hline $\begin{array}{l}\text { Complementary } \\
\text { medicine }\end{array}$ & $\begin{array}{l}\text { Providers for specific services } \\
\text { (e.g., art and music therapist, } \\
\text { yoga instructor) }\end{array}$ & $\begin{array}{l}\text { Space and equipment for services } \\
\text { (e.g., yoga, art therapy, music } \\
\text { therapy, acupuncture) }\end{array}$ \\
\hline Fertility & $\begin{array}{l}\text { Gynecologist, urologist, } \\
\text { reproductive endocrinologist }\end{array}$ & $\begin{array}{l}\text { Mechanism for counseling and } \\
\text { referral for fertility preservation }\end{array}$ \\
\hline $\begin{array}{l}\text { Financial support and } \\
\text { navigation }\end{array}$ & $\begin{array}{l}\text { Financial coordinator, care } \\
\text { coordinator, social worker }\end{array}$ & $\begin{array}{l}\text { Workspace, access to extramural and } \\
\text { community services and grants, } \\
\text { assistance for local housing }\end{array}$ \\
\hline Genetic counseling & Genetic counselors & Clinic space \\
\hline Home care services & $\begin{array}{l}\text { Patient navigator, social worker, } \\
\text { nurse }\end{array}$ & $\begin{array}{l}\text { Infrastructure to provide lab } \\
\text { services, medication administration, } \\
\text { and other care at home }\end{array}$ \\
\hline $\begin{array}{l}\text { Pain and symptom } \\
\text { management }\end{array}$ & $\begin{array}{l}\text { Palliative care physician/ } \\
\text { advance practice provider and } \\
\text { nurse, physical therapist, } \\
\text { occupational therapist, } \\
\text { rehabilitation medicine } \\
\text { provider, nutrition therapist }\end{array}$ & $\begin{array}{l}\text { Clinic space, space and equipment } \\
\text { for rehabilitation services, liaison } \\
\text { with hospice services }\end{array}$ \\
\hline $\begin{array}{l}\text { Patient information and } \\
\text { education }\end{array}$ & $\begin{array}{l}\text { Patient navigator, nurse } \\
\text { coordinator, social worker }\end{array}$ & $\begin{array}{l}\text { Patient resource library, information } \\
\text { technology support for patient } \\
\text { education, workspace, and meeting } \\
\text { rooms }\end{array}$ \\
\hline Pharmacy & Pharmacist & $\begin{array}{l}\text { Pharmacy space, supply chain to } \\
\text { provide access to chemotherapeutic } \\
\text { and supportive care drugs. }\end{array}$ \\
\hline $\begin{array}{l}\text { Psychological } \\
\text { assessment and support }\end{array}$ & $\begin{array}{l}\text { Social worker, psychiatrist, } \\
\text { psychologist, spiritual care } \\
\text { providers (e.g., chaplain) }\end{array}$ & $\begin{array}{l}\text { Clinic space, technology support for } \\
\text { assessments, support groups, access } \\
\text { to community resources for } \\
\text { psychological support, liaison with } \\
\text { other psychiatric services in the } \\
\text { institution }\end{array}$ \\
\hline $\begin{array}{l}\text { Special populations } \\
\text { (e.g., pediatric, } \\
\text { adolescent, young } \\
\text { adult, and geriatric } \\
\text { patients) }\end{array}$ & $\begin{array}{l}\text { Clinical providers with } \\
\text { expertise in treating specific } \\
\text { patient populations }\end{array}$ & $\begin{array}{l}\text { Clinic space, other support services } \\
\text { geared specifically towards special } \\
\text { populations }\end{array}$ \\
\hline
\end{tabular}


Table 11.1 (continued)

\begin{tabular}{l|l|l}
\hline Domain & Personnel support & Infrastructure support \\
\hline $\begin{array}{l}\text { Special services (e.g., } \\
\text { post-laryngectomy, } \\
\text { ostomy care, speech } \\
\text { pathology) }\end{array}$ & $\begin{array}{l}\text { Physician, advance practice } \\
\text { provider, nurse, or other } \\
\text { providers based on need }\end{array}$ & $\begin{array}{l}\text { Clinic space, equipment, and other } \\
\text { support based on specific scenario }\end{array}$ \\
\hline Survivorship care & $\begin{array}{l}\text { Advance practice providers or } \\
\text { nurses, social worker, } \\
\text { specialists, patient navigator, } \\
\text { care coordinator }\end{array}$ & $\begin{array}{l}\text { Clinic space, resources for patient } \\
\text { education, resources for generating } \\
\text { and provision of survivorship care } \\
\text { plan }\end{array}$ \\
\hline
\end{tabular}

selected patients to psychiatry. Access to a psychiatrist who specializes in the care of cancer survivors is desirable. There is robust evidence for several non-pharmacological measures for the treatment of distress and mood disorders. Several meta-analyses have demonstrated beneficial effect of exercise on overall reduction in depressive symptoms among cancer survivors [10,11]. Hence, providing services and transportation for a structured exercise program to selected patients can be beneficial and improve their quality of life. Cognitive-behavioral therapy [CBT] is effective for the treatment of PTSD in general population [12], and is also recommended for cancer survivors with PTSD [4]. Data on the efficacy of integrative medicine in improving the mental health of cancer survivors is limited. However, mindfulness-based stress reduction [MBSR] has the highest quality evidence on improving mental health in breast cancer survivors. A randomized controlled trial [RCT] on 322 breast cancer survivors showed that patients undergoing MBSR had improvement in psychological symptoms of anxiety, fear of recurrence, and fatigue compared to usual care, with the magnitude of benefit being greatest among patients with highest levels of baseline stress [13]. Notably, the intervention consisted of weekly 2-hour sessions for 6 weeks conducted by a clinical psychologist trained in MBSR, with the meditative practices consisting of sitting meditation, walking meditation, body scan, and gentle Hatha Yoga. Similar results have been replicated by other RCTs as well [14-16]. Hence, providing integrative and lifestyle medicine services to cancer survivors can be beneficial, especially for those with distress due to fear of recurrence or persistent fatigue. Online or distance sessions should also be provided for patients who cannot attend in person due to logistical reasons. At the Cleveland Clinic's Taussig Cancer Center, we provide free Yoga classes by a certified yoga instructor and a registered nurse. Furthermore, the Integrative and Lifestyle Medicine Institute at the Cleveland Clinic also provides classes on Yoga and mindfulness meditation.

\section{Fatigue}

Fatigue in cancer survivors is defined as emotional, physical, or cognitive tiredness as a result of cancer or its treatment that can interfere with activities of daily living [4]. The putative mechanisms for cancer-related fatigue are pro-inflammatory state, dysregulation of hypothalamic-pituitary-adrenal axis, skeletal muscle wasting, 
genetics, and psychosocial/ behavioral factors, among others [17]. A large study on cancer survivors from the PROFILES registry showed a high incidence of fatigue at $39-51 \%$ among cancer survivors, depending on the tumor type [18]. Persistent fatigue can lead to impaired health-related quality of life $[\mathrm{HRQOL}]$ and a decreased likelihood of staying employed [4]. The NCCN guidelines recommend that oncologists should screen cancer survivors for fatigue, based on patients' description of their fatigue level. Several patient-reported questionnaires such as Brief Fatigue Inventory $[\mathrm{BFI}]$ are also available that can be used for screening [19].

\section{Services Required for Management}

The first step in the management of fatigue is to identify and treat the contributing factors, if any, such as pain, nausea, or dyspnea [4]. An RCT from the Netherlands showed superiority of nurse-led monitoring and treatment of physical symptoms over usual care in alleviating fatigue as well as interference of fatigue with daily living in cancer survivors [20]. The symptoms that were of major concern to fatigued patients were pain, shortness of breath, and decreased appetite.

Increasing physical activity has category 1 recommendation for the management of fatigue in cancer survivors [4]. A Cochrane systematic review had studied the impact of exercise on cancer-related fatigue, as observed in RCTs [21]. At the end of study intervention period, patients who were randomized to exercise intervention had significantly lower fatigue compared to those in the control arm, especially in breast and prostate cancer survivors [21]. Subsequently, another large meta-analysis compared exercise, psychological, and pharmaceutical treatments for the treatment of cancer-related fatigue [22]. Interestingly, exercise, exercise plus psychological, and psychological interventions all led to a statistically significant as well as clinically meaningful decrease in fatigue at the end of intervention period, whereas pharmaceutical interventions did not. The absolute mean weighted effect size was numerically highest with exercise intervention [22]. Referral to a physical therapist or an exercise specialist should be strongly considered for cancer survivors who are at a risk of injury, for example, survivors with bone metastasis.

Several psychosocial and behavioral interventions, such as MBSR, CBT, psychoeducational therapy, support groups, and journal writing, have shown promise in the treatment of cancer-related fatigue. A meta-analysis of RCTs on behavioral and psychosocial interventions showed a statistically significant reduction in fatigue, depression, anxiety, and stress [23]. Acupuncture is also considered to be an acceptable option for cancer-related fatigue; however, data from RCTs have been conflicting thus far [24, 25].

\section{Pain}

Pain is one of the most concerning symptoms that is prevalent in approximately one-third of cancer survivors and can lead to depression, lack of sleep, and poor quality of life [26]. There is a diverse etiology of pain in cancer survivors, including 
arthralgia in breast cancer patients on aromatase inhibitors and neuropathic pain in patients with chemotherapy-induced peripheral neuropathy. The NCCN guidelines recommend periodic screening for pain in all survivors. Survivors with chronic pain should have easy access to pain management or palliative care specialists under a shared care model. The non-pharmacologic management strategies with a robust evidence base and the services required are summarized below.

\section{Services Required for Management}

Several behavioral approaches have been studied for pain management in a randomized fashion. In breast cancer survivors with late post-treatment pain, an 8-week mindfulness-based cognitive intervention led to a significantly decreased pain intensity, nonprescription pain medication use, and improved quality of life compared to usual care in an RCT [27]. Another RCT of sedative music therapy from Taiwan showed a significant decrease in post-intervention pain [28]. Other psychosocial support and behavioral interventions that have been shown to be effective in alleviating cancer-related pain are breathing exercises, relaxation, guided imagery, and hypnosis [29, 30]. There is a high-level evidence for increased physical activity and exercise in the management of cancer-related pain. An RCT of exercise intervention [including aerobic exercise and supervised strength training] in breast cancer survivors with aromatase inhibitor-induced arthralgia showed a significantly lower worst pain score, pain severity, and interference with activities of daily living at the end of 12-month period in the exercise arm [31]. A Yoga intervention for cancer survivors also showed decrease in musculoskeletal symptoms, including general pain, muscle ache, and physical discomfort among breast cancer survivors in an RCT [32].

Given pain being highly prevalent in cancer survivors, comprehensive cancer centers should consider provision of these services, including access to physical therapist or an exercise specialist, and classes for several behavioral interventions like mindfulness or relaxation techniques.

\section{Cognitive Dysfunction}

Cognitive dysfunction is a well-described long-term side effect of cytotoxic chemotherapy and is associated with impaired functioning and quality of life [33]. An online survey named LIVESTRONG 2010 was conducted between June 2010 and March 2011 on 3108 post-treatment cancer survivors to investigate perceived cognitive dysfunction and depressive symptoms [34]. Approximately one-half of respondents reported current perceived cognitive dysfunction, with the highest prevalence among brain tumor survivors. Notably, perceived cognitive dysfunction was associated with receiving chemotherapy and self-reported depressive symptoms. The current NCCN guidelines acknowledge the lack of effective screening tool for cognitive 
dysfunction and recommends clinicians to use their judgement and perform appropriate workup in patients who self-report cognitive dysfunction. Several questions that can assess patients' ability to perform activities of daily living and instrumental activities of daily living may help clinicians uncover subtle cognitive dysfunction.

\section{Services Required for Management}

Apart from simple non-pharmacological interventions such as deprescribing unnecessary medications and instruction in self-management, robust data on efficacy of behavioral interventions are lacking. In a small RCT, cognitive behavioral therapy [CBT] was shown to improve spiritual well-being and verbal memory in breast cancer survivors but did not have any impact on self-reported daily cognitive complaints [35]. Another small RCT of videoconference-delivered CBT in breast cancer survivors showed significant improvement in perceived cognitive function and neuropsychological processing speed compared to controls who received supportive care [36]. Similar to its impact on other psychosocial and physical effects, structured exercise program offers benefit to patients with cognitive dysfunction as well, with a dose-response relationship observed with greater levels of physical activity [37]. Other services that can offer benefit to patients with cognitive dysfunction include cognitive training [38], relaxation, meditation [39], and Yoga [40].

\section{Services for Healthy Lifestyle in Cancer Survivors}

Maintaining a healthy lifestyle in cancer survivors, including regular physical activity, a balanced diet, and avoiding tobacco smoking, is associated with superior outcomes in several tumor types [41-43]. There is a robust evidence on the impact of physical activity in reducing the risk of cardiovascular events in cancer survivors. Data from the Childhood Cancer Survivors Study demonstrated the impact of exercise on cardiovascular events in Hodgkin Lymphoma survivors at a median followup of approximately 12 years [44]. Furthermore, the impact of exercise was dose-dependent, with the risk of cardiovascular events being significantly lower among patients reporting $\geq 9$ METs [metabolic equivalent hours]/week. Similar results were seen among patients with nonmetastatic breast cancer [45]. The current NCCN guidelines recommend periodic assessment of physical activity level in cancer survivors. A questionnaire survey of 975 cancer survivors identified several barriers for physical activity, including lack of time, lack of access to an exercise environment, uncertainty regarding safety of exercise post-cancer treatment, physical limitations, and lack of knowledge regarding appropriate physical activities [46]. Hence, providing access to a formal exercise program within comprehensive cancer centers can be beneficial to patients and help provide an individualized exercise plan to survivors. Offering behavioral strategies, including telephone counselling, print material on benefits of physical activity, and motivational interviews can 
also be helpful in increasing physical activity among cancer survivors. Providing tailored print materials to cancer survivors by mail, promoting consumption of fruits and vegetables, reducing fat intake, and increasing exercise has been shown to be superior to providing standardized non-tailored materials in an RCT [47]. At Taussig Cancer Center, we also provide a mentoring program for cancer survivors called as 4th Angel Patient and Caregiver Mentoring Program, as a part of which, patients and their caregivers are connected with similar cancer survivors who can share their experiences and provide emotional and spiritual guidance.

\section{Survivorship Care Models}

A "model" for providing survivorship care is defined as a comprehensive approach for follow-up care of survivors, which can be performed by the oncology team or primary care providers or both [48]. Designing a strategy for caring for long-term cancer survivors is an integral part of most comprehensive cancer centers and has been endorsed by the American Society of Clinical Oncology [48]. A large systematic review has demonstrated that cancer survivors benefit from coordinated posttreatment psychosocial, rehabilitative, and supportive care [48]. Table 11.2 provides guidance on various elements and domains of cancer survivorship care that cancer centers should strive to achieve.

Table 11.2 Various aspects of survivorship care provided by comprehensive cancer centers

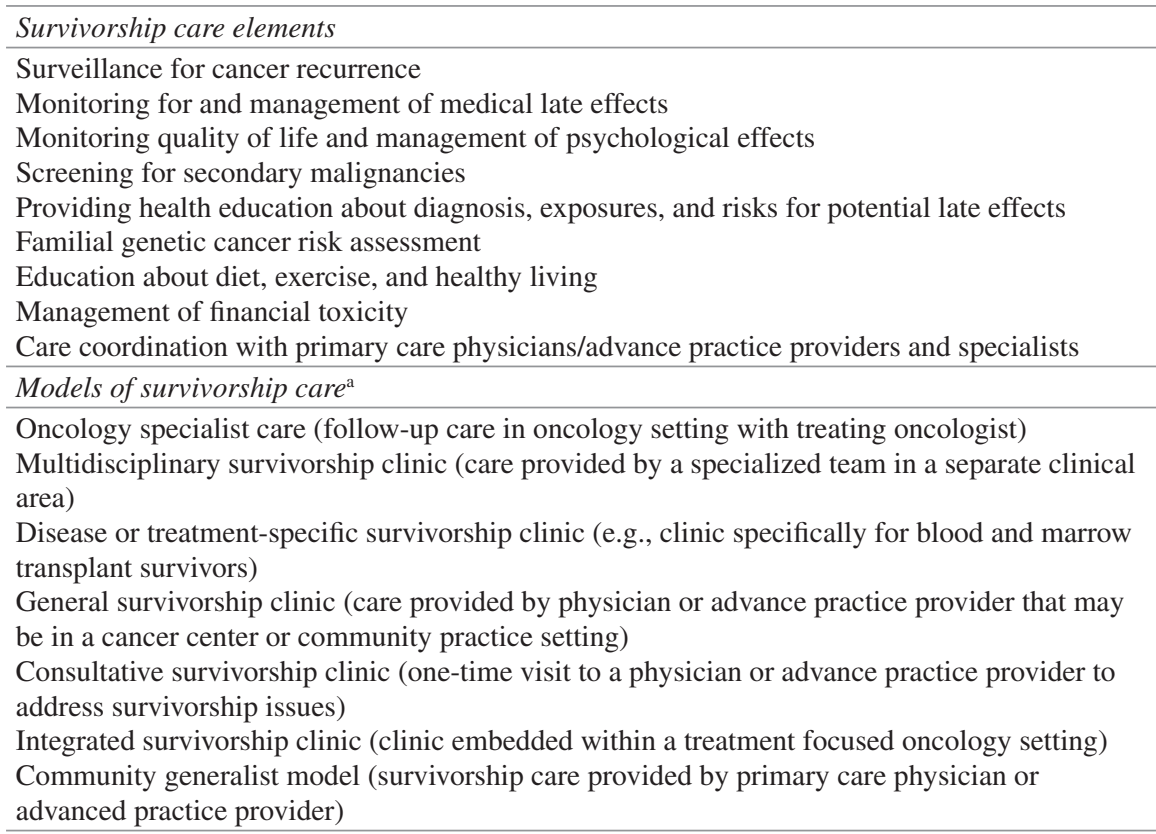
${ }^{a}$ According to American Society of Clinical Oncology (https://www.asco.org/practice-policy/ cancer-care-initiatives/prevention-survivorship/survivorship/survivorship-3; accessed 09/01/2020) 
Survivorship care models are usually described by the type of survivors [tumorspecific versus general], care setting [separate survivorship clinic versus integrated model], type of clinician(s) providing survivorship care [physician-led versus nurseled versus nurse practitioner-led versus shared-care model], or the purpose of the survivorship program [e.g., transition clinic model] [48]. The Institute of Medicine recommendations have identified four key domains of survivorship care: prevention, surveillance, intervention, and coordination [3]. To our knowledge, there are three large randomized controlled trials that empirically tested different survivorship care models. Wattchow et al from Australia randomized patients with early stage colon cancer who had underwent curative-intent surgery followed by postsurgical chemotherapy to follow-up by general practitioners [primary care] or surgeons [secondary care] for five years, with the prescribed frequency being every three months for the first two years followed by every two months for the subsequent three years [49]. The primary outcome measures, which were measured at 12 and 24 months, were (a) physical and mental quality of life (b) anxiety and depression, and (c) patient satisfaction. At both 12 and 24 months, there was not any clinically meaningful or statistically significant difference in the primary endpoints between the two care groups. Furthermore, the recurrence rate, time to recurrence detection, and death rate were also similar in both groups. Another Canadian study randomized early stage breast cancer survivors who had completed adjuvant chemotherapy + - - radiotherapy to follow-up by the cancer center [CC group] or their own family physician [FP group]. Of note, patients were allowed to receive hormonal therapy during the study period [50]. The primary outcome of the study was rate of recurrence-related serious clinical events, and the secondary outcome was healthrelated quality of life. There was no difference in the primary or secondary outcomes in either group. The total number of breast cancer recurrences and deaths was similar in both groups. Notably, family physicians in this study were provided follow-up guidelines, including frequency of follow-up, yearly mammogram, diagnostic tests to investigate signs or symptoms of new primary cancers, and close surveillance for vaginal bleeding in patients on tamoxifen. Hence, based on these two studies, a transition clinic model of survivorship care, which focuses on transition of care from specialists to PCPs, should provide results comparable to continued survivorship care at cancer centers, as long as PCPs are provided specific guidance and expectations regarding long-term toxicities, late effects, and signs of disease recurrence. In a survey of PCPs caring for adult survivors of hematopoietic cell transplantation $[\mathrm{HCT}]$ in the United States, commonly identified barriers to care delivery were lack of resources to facilitate care, lack of awareness regarding screening/prevention guidelines in HCT survivors, lack of awareness regarding psychosocial needs, inadequate time, and preference of patients to follow-up with their oncologists [51]. Several of these factors can be potentially addressed by providing education, tools for clinical decision making, and guidelines to PCPs caring for cancer survivors. Finally, a third RCT assessed the cost of follow-up in breast cancer survivors by randomizing them into four different treatment schedules [52]. The four schedules differed either in the frequency of visits [every third or sixth month] or in the intensity of diagnostic tests [on a routine basis versus specific clinical 
grounds]. Neither increasing the visit frequency to every three months nor performing routine diagnostic examinations led to any benefit in disease-free or overall survival despite increasing the cost of care.

Providing patients and their PCPs with a survivorship care plan [SCP] has been endorsed as a key component of survivor care by the Institute of Medicine [3]. However, the evidence on impact of SCPs on health outcomes and health care delivery is conflicting. A large systematic review including 13 randomized studies on SCPs showed largely negative results regarding impact on physical, psychological, and functional well-being, which were the most commonly assessed outcomes [53]. On the other hand, positive findings on proximal outcomes such as the amount of information received, care satisfaction, and physician implementation of recommended care was noted in some studies. One of the major limitations of this review was heterogeneity in study design. A study conducted at ten cancer centers within the NCI-funded Cancer Research Network in the United States showed that oncology and primary care were jointly responsible for the care of cancer survivors, similar to a shared-care model [54]. However, only two out of ten sites had a formal survivorship program in place. Issues with patient finances and insurance reimbursement were also a major area of concern. At the Cleveland Clinic Blood and Marrow Transplant department, we have established a formal survivorship program since 2016 [55]. Since BMT survivors have unique health care needs due to late effects like chronic graft versus host disease, infections, and second cancers, lifelong follow-up and monitoring is recommended according to most guidelines, which prompted us to develop the survivorship program. A sharedcare model, in which BMT physician and PCP liaise to provide ongoing care along with referral to other subspecialty services when needed, was thought to be the most appropriate for this patient population. The program consists of day 100 and 1-year survivorship visit by NP, a treatment summary, and care plan developed by the NP on day 100 and 1-year post-transplant for all non-relapsed patients, and development of educational materials. At the 1-year visit, the NP provides patients, their PCPs, and the primary BMT physician with a summary of test results and a revised care plan, which includes recommended screening/preventative guidelines. Hence, development of a successful survivorship program requires several elements, including appropriate consideration of patient and disease-related factors, buy-in from department leadership, allocation of sufficient resources and personnel, and finally, identifying physician champions in different specialties which will be involved in patient care. Finally, as seen in a recent review [48], survivorship care models are highly institution-dependent, which highlights the need for further research in this area to identify optimal care models.

\section{Community Outreach}

Finally, comprehensive cancer centers should also engage in community outreach to especially target high-risk population with the goal of early cancer detection to improve outcome. Cleveland Clinic Cancer Center offers cancer prevention, screening, education and navigation programs designed to meet the needs of the diverse community we serve. 
We work with local churches, schools, and other nongovernmental organizations. Our partnership with Federally Qualified Health Centers (FQHC) to provide screening services is very unique. Since there are data on delay in cancer treatment initiation among minorities and low-income population [56], our goal is to reduce the disparity by providing preventative education, cancer risk assessments, and recommended screening including mammogram, prostate exam, colonoscopy, low-dose chest CT, and oral cancer screening for appropriate population. If cancer is found, our Cleveland Clinic Cancer Center community outreach patient navigators can also help with providing cancer education and resources, scheduling appointments, arranging transportation, navigating treatments, providing support during appointments, and offering financial guidance.

\section{Patient Support and Psychosocial Services in Resource-Limited Settings}

Provision of patient support and psychosocial services (see Table 11.1) are an essential component of comprehensive cancer care. Although not directly related to treatment of underlying cancer, they ultimately impact patient access to care and optimal outcomes. Cancer centers in resource-limited setting should strive to provide these services to patients while recognizing and prioritizing services that are most relevant to their local patients and communities. For example, in areas where cancer care is largely subsidized by the government, there may not be much need for personnel who need to focus on financial navigation for patients. On the other hand, some elements comprise basic cancer care and should be considered in the planning phase of developing a cancer center such that personnel and infrastructure investments can be made early on. Examples of such services include social work, palliative care, and survivorship care. In several resource-limited settings, local and regional health care in areas other cancer may be better developed - an attempt should be made to identify, optimize, and share existing resources. In these settings, cancer care is often provided by the government and advocating with policy makers to emphasize the importance of psychosocial and patient support services often needed to ensure sufficient resources and infrastructure is assigned towards their development. Ultimately a needs assessment is required as a cancer center is being established with the plan to bring in these services early and focus on domains that will have the most impact on patients and local communities.

\section{References}

1. Miller KD, Siegel RL, Lin CC, et al. Cancer treatment and survivorship statistics, 2016. CA Cancer J Clin. 2016;66(4):271-89.

2. Deshields T, Zebrack B, Kennedy V. The state of psychosocial services in cancer care in the United States. Psycho-Oncology. 2013;22(3):699-703.

3. Nekhlyudov L, Ganz PA, Arora NK, Rowland JH. Going beyond being lost in transition: a decade of progress in cancer survivorship. J Clin Oncol. 2017;35(18):1978-81. 
4. Sanft T, Denlinger CS, Armenian S, et al. NCCN guidelines insights: survivorship, version 2.2019. J Natl Compr Cancer Netw. 2019;17(7):784-94.

5. Riba MB, Donovan KA, Andersen B, et al. Distress management, version 3.2019, NCCN clinical practice guidelines in oncology. J Natl Compr Cancer Netw. 2019;17(10):1229-49.

6. Ploos van Amstel FK, van den Berg SW, van Laarhoven HW, Gielissen MF, Prins JB, Ottevanger PB. Distress screening remains important during follow-up after primary breast cancer treatment. Support Care Cancer. 2013;21(8):2107-15.

7. Roerink SH, de Ridder M, Prins J, et al. High level of distress in long-term survivors of thyroid carcinoma: results of rapid screening using the distress thermometer. Acta oncologica (Stockholm, Sweden). 2013;52(1):128-37.

8. Carmack CL, Basen-Engquist K, Gritz ER. Survivors at higher risk for adverse late outcomes due to psychosocial and behavioral risk factors. Cancer Epidemiol Biomark Preven: a publication of the American Association for Cancer Research, cosponsored by the American Society of Preventive Oncology. 2011;20(10):2068-77.

9. Swartzman S, Booth JN, Munro A, Sani F. Posttraumatic stress disorder after cancer diagnosis in adults: a meta-analysis. Depress Anxiety. 2017;34(4):327-39.

10. Brown JC, Huedo-Medina TB, Pescatello LS, et al. The efficacy of exercise in reducing depressive symptoms among cancer survivors: a meta-analysis. PLoS One. 2012;7(1):e30955.

11. Zhu G, Zhang X, Wang Y, Xiong H, Zhao Y, Sun F. Effects of exercise intervention in breast cancer survivors: a meta-analysis of 33 randomized controlled trails. Onco Targets Ther. 2016;9:2153-68.

12. Mendes DD, Mello MF, Ventura P, Passarela Cde M, Mari JJ. A systematic review on the effectiveness of cognitive behavioral therapy for posttraumatic stress disorder. Int J Psychiatry Med. 2008;38(3):241-59.

13. Lengacher CA, Reich RR, Paterson CL, et al. Examination of broad symptom improvement resulting from mindfulness-based stress reduction in breast cancer survivors: a randomized controlled trial. J Clin Oncol. 2016;34(24):2827-34.

14. Bower JE, Crosswell AD, Stanton AL, et al. Mindfulness meditation for younger breast cancer survivors: a randomized controlled trial. Cancer. 2015;121(8):1231-40.

15. Carlson LE, Doll R, Stephen J, et al. Randomized controlled trial of mindfulness-based cancer recovery versus supportive expressive group therapy for distressed survivors of breast cancer. J Clin Oncol. 2013;31(25):3119-26.

16. Carlson LE, Tamagawa R, Stephen J, Drysdale E, Zhong L, Speca M. Randomized-controlled trial of mindfulness-based cancer recovery versus supportive expressive group therapy among distressed breast cancer survivors (MINDSET): long-term follow-up results. PsychoOncology. 2016;25(7):750-9.

17. Bower JE. Cancer-related fatigue--mechanisms, risk factors, and treatments. Nat Rev Clin Oncol. 2014;11(10):597-609.

18. Husson O, Mols F, van de Poll-Franse L, de Vries J, Schep G, Thong MS. Variation in fatigue among 6011 (long-term) cancer survivors and a normative population: a study from the population-based PROFILES registry. Support Care Cancer. 2015;23(7):2165-74.

19. Mendoza TR, Wang XS, Cleeland CS, et al. The rapid assessment of fatigue severity in cancer patients: use of the Brief Fatigue Inventory. Cancer. 1999;85(5):1186-96.

20. de Raaf PJ, de Klerk C, Timman R, Busschbach JJ, Oldenmenger WH, van der Rijt CC. Systematic monitoring and treatment of physical symptoms to alleviate fatigue in patients with advanced cancer: a randomized controlled trial. J Clin Oncol. 2013;31(6):716-23.

21. Cramp F, Byron-Daniel J. Exercise for the management of cancer-related fatigue in adults. Cochrane Database Syst Rev. 2012;11:Cd006145.

22. Mustian KM, Alfano CM, Heckler C, et al. Comparison of pharmaceutical, psychological, and exercise treatments for cancer-related fatigue: a meta-analysis. JAMA Oncol. 2017;3(7):961-8.

23. Duijts SF, Faber MM, Oldenburg HS, van Beurden M, Aaronson NK. Effectiveness of behavioral techniques and physical exercise on psychosocial functioning and health-related 
quality of life in breast cancer patients and survivors--a meta-analysis. Psycho-Oncology. 2011;20(2):115-26.

24. Posadzki P, Moon TW, Choi TY, Park TY, Lee MS, Ernst E. Acupuncture for cancerrelated fatigue: a systematic review of randomized clinical trials. Support Care Cancer. 2013;21(7):2067-73.

25. Zeng Y, Luo T, Finnegan-John J, Cheng AS. Meta-analysis of randomized controlled trials of acupuncture for cancer-related fatigue. Integr Cancer Ther. 2014;13(3):193-200.

26. Pachman DR, Barton DL, Swetz KM, Loprinzi CL. Troublesome symptoms in cancer survivors: fatigue, insomnia, neuropathy, and pain. J Clin Oncol. 2012;30(30):3687-96.

27. Johannsen M, O'Connor M, O'Toole MS, Jensen AB, Hojris I, Zachariae R. Efficacy of mindfulness-based cognitive therapy on late post-treatment pain in women treated for primary breast cancer: a randomized controlled trial. J Clin Oncol. 2016;34(28):3390-9.

28. Huang ST, Good M, Zauszniewski JA. The effectiveness of music in relieving pain in cancer patients: a randomized controlled trial. Int J Nurs Stud. 2010;47(11):1354-62.

29. Cassileth BR, Keefe FJ. Integrative and behavioral approaches to the treatment of cancerrelated neuropathic pain. Oncologist. 2010;15(Suppl 2):19-23.

30. Kwekkeboom KL, Cherwin CH, Lee JW, Wanta B. Mind-body treatments for the painfatigue-sleep disturbance symptom cluster in persons with cancer. J Pain Symptom Manag. 2010;39(1):126-38.

31. Irwin ML, Cartmel B, Gross CP, et al. Randomized exercise trial of aromatase inhibitorinduced arthralgia in breast cancer survivors. J Clin Oncol. 2015;33(10):1104-11.

32. Peppone LJ, Janelsins MC, Kamen C, et al. The effect of YOCAS(c)(R) yoga for musculoskeletal symptoms among breast cancer survivors on hormonal therapy. Breast Cancer Res Treat. 2015;150(3):597-604.

33. Ahles TA, Saykin AJ, McDonald BC, et al. Longitudinal assessment of cognitive changes associated with adjuvant treatment for breast cancer: impact of age and cognitive reserve. $\mathrm{J}$ Clin Oncol. 2010;28(29):4434-40.

34. Schmidt JE, Beckjord E, Bovbjerg DH, et al. Prevalence of perceived cognitive dysfunction in survivors of a wide range of cancers: results from the 2010 LIVESTRONG survey. J Cancer Survivorship Res Pract. 2016;10(2):302-11.

35. Ferguson RJ, McDonald BC, Rocque MA, et al. Development of CBT for chemotherapy-related cognitive change: results of a waitlist control trial. Psycho-Oncology. 2012;21(2):176-86.

36. Ferguson RJ, Sigmon ST, Pritchard AJ, et al. A randomized trial of videoconference-delivered cognitive behavioral therapy for survivors of breast cancer with self-reported cognitive dysfunction. Cancer. 2016;122(11):1782-91.

37. Hartman SJ, Nelson SH, Myers E, et al. Randomized controlled trial of increasing physical activity on objectively measured and self-reported cognitive functioning among breast cancer survivors: the memory \& motion study. Cancer. 2018;124(1):192-202.

38. Chan RJ, McCarthy AL, Devenish J, Sullivan KA, Chan A. Systematic review of pharmacologic and non-pharmacologic interventions to manage cognitive alterations after chemotherapy for breast cancer. Eur J Cancer (Oxford, England : 1990). 2015;51(4):437-50.

39. Johns SA, Von Ah D, Brown LF, et al. Randomized controlled pilot trial of mindfulness-based stress reduction for breast and colorectal cancer survivors: effects on cancer-related cognitive impairment. J Cancer Survivorship Res Pract. 2016;10(3):437-48.

40. Derry HM, Jaremka LM, Bennett JM, et al. Yoga and self-reported cognitive problems in breast cancer survivors: a randomized controlled trial. Psycho-Oncology. 2015;24(8):958-66.

41. Campbell PT, Patel AV, Newton CC, Jacobs EJ, Gapstur SM. Associations of recreational physical activity and leisure time spent sitting with colorectal cancer survival. J Clin Oncol. 2013;31(7):876-85.

42. Kabat GC, Matthews CE, Kamensky V, Hollenbeck AR, Rohan TE. Adherence to cancer prevention guidelines and cancer incidence, cancer mortality, and total mortality: a prospective cohort study. Am J Clin Nutr. 2015;101(3):558-69. 
43. Van Blarigan EL, Fuchs CS, Niedzwiecki D, et al. Association of survival with adherence to the American Cancer Society nutrition and physical activity guidelines for cancer survivors after colon cancer diagnosis: the CALGB 89803/Alliance trial. JAMA Oncol. 2018;4(6):783-90.

44. Jones LW, Liu Q, Armstrong GT, et al. Exercise and risk of major cardiovascular events in adult survivors of childhood hodgkin lymphoma: a report from the childhood cancer survivor study. J Clin Oncol. 2014;32(32):3643-50.

45. Jones LW, Habel LA, Weltzien E, et al. Exercise and risk of cardiovascular events in women with nonmetastatic breast cancer. J Clin Oncol. 2016;34(23):2743-9.

46. Blaney JM, Lowe-Strong A, Rankin-Watt J, Campbell A, Gracey JH. Cancer survivors' exercise barriers, facilitators and preferences in the context of fatigue, quality of life and physical activity participation: a questionnaire-survey. Psycho-Oncology. 2013;22(1):186-94.

47. Demark-Wahnefried W, Clipp EC, Lipkus IM, et al. Main outcomes of the FRESH START trial: a sequentially tailored, diet and exercise mailed print intervention among breast and prostate cancer survivors. J Clin Oncol. 2007;25(19):2709-18.

48. Halpern MT, Viswanathan M, Evans TS, Birken SA, Basch E, Mayer DK. Models of cancer survivorship care: overview and summary of current evidence. J Oncol Pract. 2015;11(1):e19-27.

49. Wattchow DA, Weller DP, Esterman A, et al. General practice vs surgical-based follow-up for patients with colon cancer: randomised controlled trial. Br J Cancer. 2006;94(8):1116-21.

50. Grunfeld E, Levine MN, Julian JA, et al. Randomized trial of long-term follow-up for earlystage breast cancer: a comparison of family physician versus specialist care. J Clin Oncol. 2006;24(6):848-55.

51. Mani S, Khera N, Rybicki L, et al. Primary care physician perspectives on caring for adult survivors of hematologic malignancies and hematopoietic cell transplantation. Clin Lymphoma Myeloma Leuk. 2020;20(2):70-7.

52. Kokko R, Hakama M, Holli K. Follow-up cost of breast cancer patients with localized disease after primary treatment: a randomized trial. Breast Cancer Res Treat. 2005;93(3):255-60.

53. Jacobsen PB, DeRosa AP, Henderson TO, et al. Systematic review of the impact of cancer survivorship care plans on health outcomes and health care delivery. J Clin Oncol. 2018;36(20):2088-100.

54. Chubak J, Tuzzio L, Hsu C, et al. Providing care for cancer survivors in integrated health care delivery systems: practices, challenges, and research opportunities. J Oncol Pract. 2012;8(3):184-9.

55. Ferraro CS, Bernhard L, Coffman J, Majhail NS, Hamilton BK. Optimizing long-term Care for Hematopoietic Cell Transplantation (HCT) survivors: framework for establishing a new Blood and Marrow Transplant (BMT) survivorship program. Biol Blood Marrow Transplant. 2018;24(3):S266.

56. Nonzee NJ, Ragas DM, Ha Luu T, et al. Delays in Cancer care among low-income minorities despite access. J Womens Health (Larchmt). 2015;24(6):506-14.

Open Access This chapter is licensed under the terms of the Creative Commons Attribution 4.0 International License (http://creativecommons.org/licenses/by/4.0/), which permits use, sharing, adaptation, distribution and reproduction in any medium or format, as long as you give appropriate credit to the original author(s) and the source, provide a link to the Creative Commons license and indicate if changes were made.

The images or other third party material in this chapter are included in the chapter's Creative Commons license, unless indicated otherwise in a credit line to the material. If material is not included in the chapter's Creative Commons license and your intended use is not permitted by statutory regulation or exceeds the permitted use, you will need to obtain permission directly from the copyright holder.

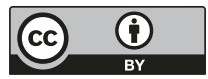

